\section{A computerized slot machine simulation to investigate the variables involved in gambling behavior}

\author{
OTTO H. MACLIN, MARK R. DIXON, \\ and LINDA J. HAYES \\ University of Nevada, Reno, Nevada
}

The present paper describes a computerized slot machine simulation designed to examine many of the potential variables involved in gambling behavior. This program was created in Visual Basic Version 6.0 and is designed to run on any Windows 95 or higher equipped computer. The program allows for experimenter manipulation of probabilities of payoffs, visual display of potential winning symbols, exact sequences of wins and losses, as well as pose run time questions to the subject on prespecified trials. The program records data on a trial-bytrial basis to a text file for easy importation into many data analysis and statistical programs. Conceptual and experimental questions that may be addressed with the described program are also discussed.

Two decades ago, 2 states in America had legal gambling, whereas 48 states outlawed it. Today, the statistic has reversed: Forty-eight states have some form of legal gambling, whereas only 2 outlaw it. With the growth of legalized gambling comes an increase in the number of individuals engaging in this type of risk-taking behavior. Many theories as to why individuals continue to gamble or to take other irrational risks focus on characteristics of the gambler as the principle variable responsible for risk taking. These hypothesized qualities range from sensationseeking personalities (Anderson \& Brown, 1984; Dickerson, Fabre, \& Bayliss, 1986) to the possession of biases and heuristics (Kahneman \& Tversky, 1972).

Positive consequences for gambling have also been shown to strengthen this behavior. When an individual who does not often make risky decisions is placed in a situation where such decisions must be made, positive consequences may increase the probability of repeated risk taking (Ladouceur, Gaboury, Dumont, \& Rochette, 1988). These findings were later supported by Dixon, Hayes, Rehfeldt, and Ebbs (1998), who demonstrated that both inexperienced and experienced roulette players would begin to take higher risk bets over time if they were winning and would shift to lower risk bets if they were losing.

By illustrating the role that the current environment plays in the maintenance of gambling behavior, these findings may provide the rationale for studying not only the characteristics of the individual who may have a ten-

Correspondence concerning this article should be addressed to $\mathrm{O} . \mathrm{H}$. MacLin, Department of Psychology, University of Nevada, Reno, NV 89557 (e-mail: otto@scs.unr.edu). Program requests should be accompanied by four blank 3.5 -in. high-density disks. dency to gamble, but also the currently operating environmental contingencies and the characteristics of the games played.

Experimental manipulations of casino-type games are very seldom conducted. First, the casino industry does not allow any form of probability adjustments to be made to their games. Second, many card and table games have set odds that cannot be manipulated. Therefore, to investigate gambling behavior from more than a descriptive perspective, computer simulations may have great utility. Computerized gambling simulations could allow for manipulation of crucial variables that may influence duration of play, size of bets made, and/or levels of risk taken.

One example of a casino-type gambling computer program was created by Dixon, MacLin, and Hayes (1999). This program simulates a casino video poker machine and allows the experimenter to change the numbers of coins the player can bet with, the maximum coins to be bet on each trial, whether a subjective probability question (asking the player to estimate how many trials it will be until he/she has a win) is displayed after optional trials, and specific magnitudes of reinforcement.

Although video poker remains a popular game in the casino, the biggest revenue generator in the casino is the slot machine (Ghezzi, Lyons, \& Dixon, in press). The slot machine requires learning very few rules in order to play: (1) insert coin(s), (2) pull lever, and (3) wait to see if you have won. The most common slot machines in the United States have three reels that contain a variety of graphical symbols. These symbols may take the forms of fruits, bars, or abstract designs. Only three positions of each wheel are visible to the slot machine player. Of these three positions, it is the middle position that is considered the payoff line. When the reels stop spinning, if three of the same symbol appear on the middle payoff line, the player wins a specified number of coins.

\section{Program Operation}

This program is written in Visual Basic 6.0 for IBMcompatible computers running under the Microsoft Windows 95 or Windows 98 operating systems. Visual Basic is an object-oriented program that uses Windows $95 / 98$ libraries to display graphical images, play audio (.wav) files, and collect responses when the subjects use the mouse to click buttons and check option boxes. Visual Basic programming code can be compiled into an executable file (.exe) and run on any IBM-compatible system with Windows $95 / 98$, without the need to purchase Visual Basic itself. This allows many users to run a Visual Basic program without adding the program language to each computer.

Using a Windows-type control panel, the experimenter can easily change the following parameters of the game before it begins: (1) the visible types of symbols that will appear on each of the three reels each time the reels are 
\$ Control Panel - For Help See ReadMe.txt

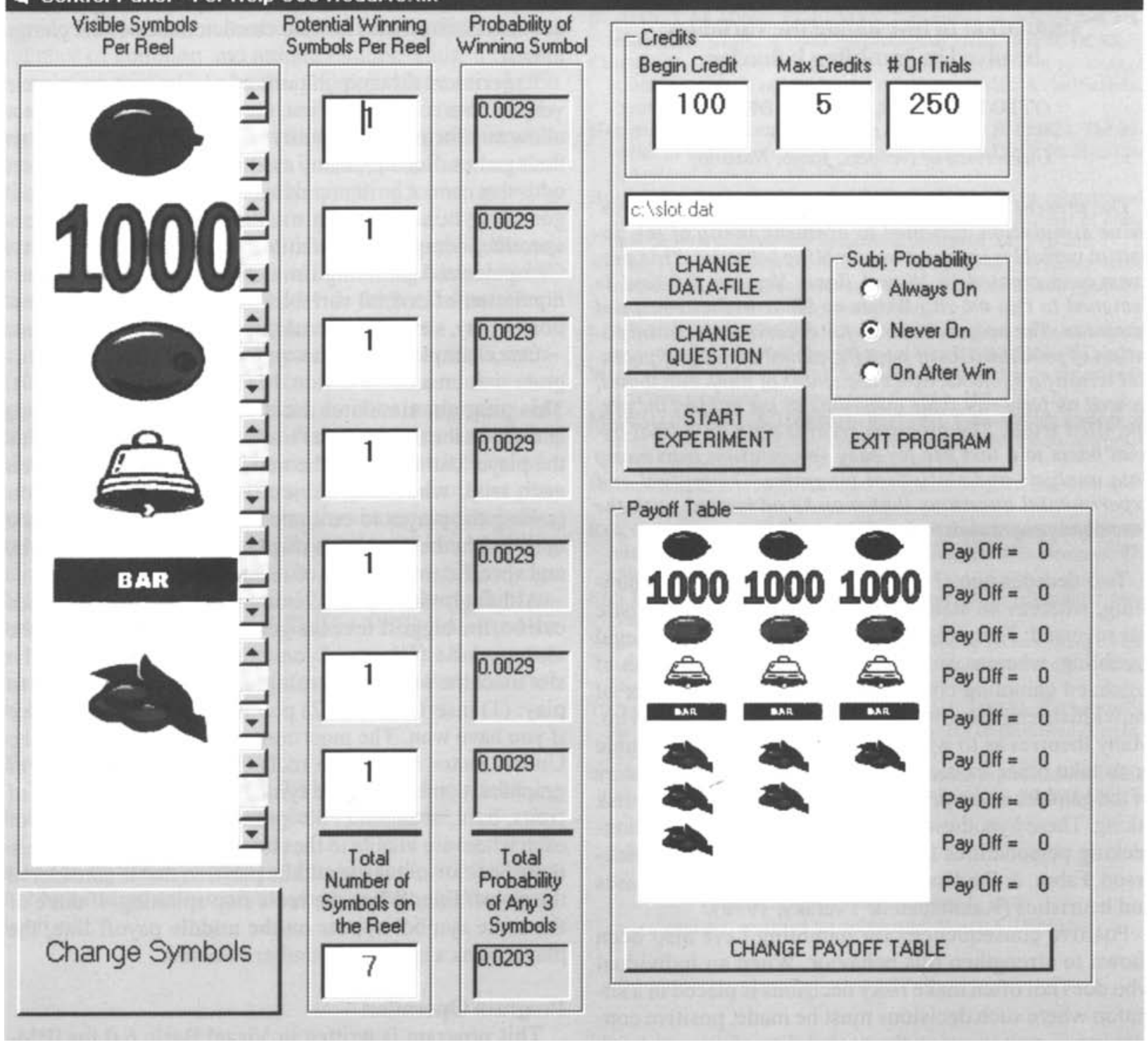

Figure 1. Control panel for the slot machine program.

spun, (2) the number of each potential winning symbol that each reel contains (by selecting a value of " 0 " for a reel symbol on Option 2, while having selected a value of " 1 " or greater for that corresponding visible symbol on Option 1, the net result during run time is that the subject will observe that visible symbol on the reels, yet that symbol will never stop on the payoff line), (3) the specific magnitudes of reinforcement for all possible winning combinations, (4) the number of coins (credits) the player begins with, (5) the maximum number of coins that can be bet on each trial, (6) whether a subjective probability question (asking the player to estimate how many trials will it be until he/she has a win) is displayed after win- ning trials, after every trial, or on no trial, and (7) the maximum number of trials the player can play. After all the parameters have been selected, the experimenter can customize the payoff table displayed during the run time of the experiment.

Figures 1 and 2 show screen graphics of the program that were designed to replicate an actual casino slot machine. Three reels, each displaying three symbols, are located across the middle portion of the monitor on a gray background before the beginning of play (see Figure 2). The middle symbol displayed on each reel is on the payoff line. Symbols above and below this line have no influence on the payoff. A payoff table is located beside the 


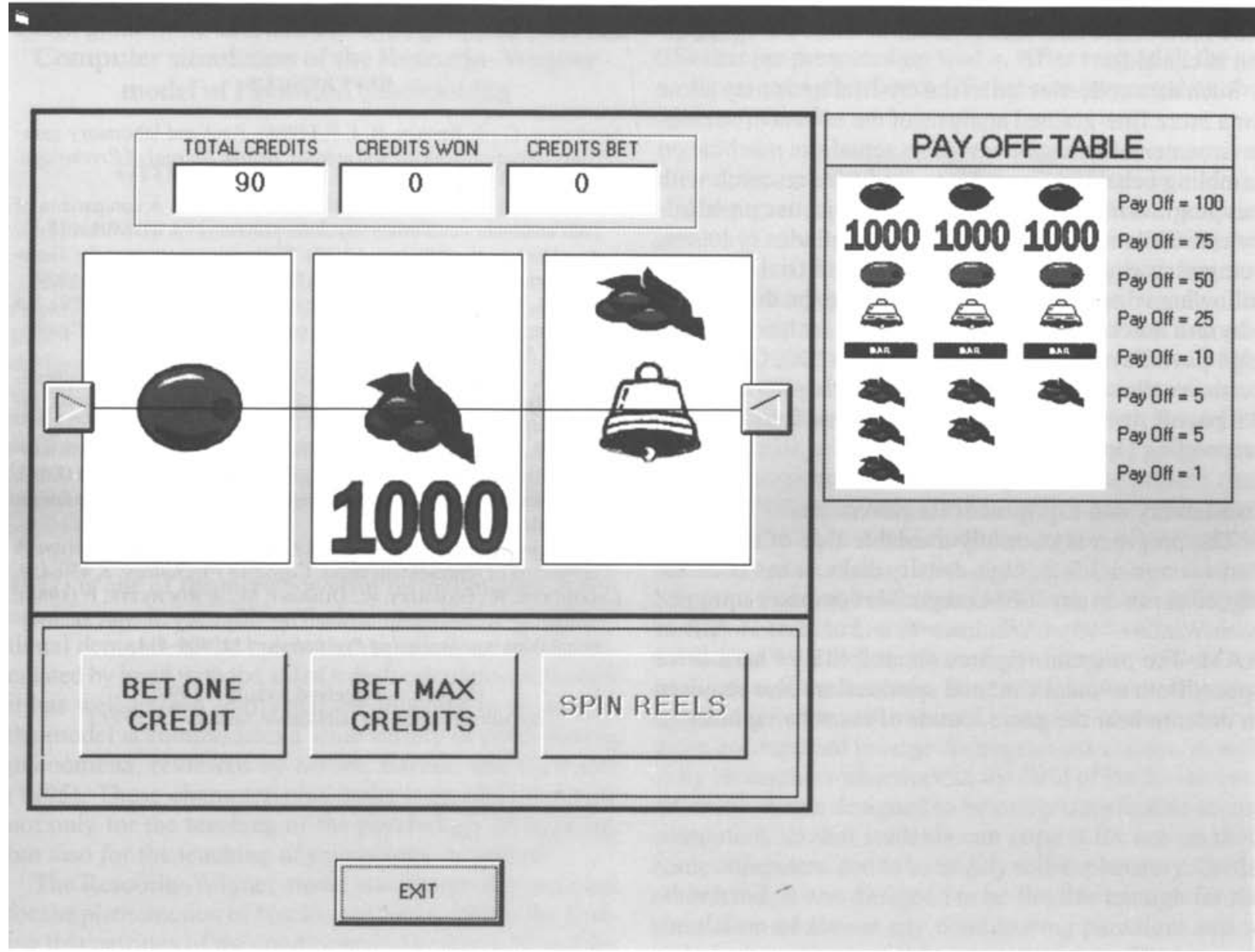

Figure 2. Slot machine and payoff table display.

reels, which indicates the winning symbol combinations and their pay out in coins. By clicking the mouse pointer on an image of a "Bet One Credit" or a "Bet Max Credits" button located in the lower center of the screen (not shown in Figure 2), the player is able to select the number of coins he or she wishes to wager on the next game. Each additional coin wagered increases the payoff table's values proportionally. For example, on a one-coin bet, three "Cherries" on the payoff line would pay one coin. On a four-coin bet, three "Cherries" on the payoff line would pay four coins. If the player is required to make subjective probability estimates of the number of trials before a winning spin, a rectangular box displaying this appears, and the player must choose a number between 1 and 20 before continuing.

Once a wager has been made, the player can click the mouse pointer on the "Spin" button to spin the reels. All the selected visible symbols (Option 1; see leftmost column of Figure 1) will appear to spin randomly on each reel. Only selected potential winning symbols (Option 2; see second column from left in Figure 1) will stop on the payoff line. If three symbols that have stopped on the payoff line meet the criteria of the payoff table, the player wins the corresponding number of coins. If three symbols do not meet the criteria, the trial ends. The number of coins paid out for that trial and the cumulative coins won for that session are displayed on the screen.

The program writes data for every trial into a text (.txt) file. The file contains comma separation between each data point so that it can easily be imported into spreadsheets, graphics, or data analysis programs. Headings are also provided for the user to identify which column of data represents which dependent measure. Responsebased measures include: coins bet, coins won, cumulative coins, subjective probability estimations (when applicable), symbols on the payoff line, symbols below the line, and symbols above the line. Time-based measures include: intertrial interval (time from the stop of the reels 
to when the next trial is instated) and total engagement time (end of the intertrial interval to when the spin button is clicked).

Such data collection on a trial-by-trial basis may allow for a more fine-grained analysis of the effects of various environmental arrangements of an actual slot machine on gambling behavior. Some ideas for future research with this program may include examining subjective probability estimations as a function of strings of wins or losses, comparing engagement times and/or intertrial intervals following wins versus losses, measuring the duration of play as a function of payoff probabilities, or having many high payoff symbols visible on the reels (i.e., Option 1), yet never allowing the reels to stop with these symbols on the payoff line (i.e., selecting 0 on Option 2 for the corresponding Option 1 symbol).

\section{Availability and Equipment Requirements}

The program is currently available free of charge. It comes on four 3.5-in. high-density disks. It has been designed to run on any IBM-compatible computer equipped with Windows 95 or Windows 98 and at least $16 \mathrm{MB}$ of RAM. The program requires about $2 \mathrm{MB}$ of hard drive space. Both a sound card and speakers are also required in order to hear the game sounds of coins being inserted into the machine, the spinning and stopping of the reels, and coins dropping out of the machine on winning trials.

\section{REFERENCES}

ANDERSON, G., \& Brown. R. I. F. (1984). Real and laboratory gambling, sensation-seeking and arousal. British Journal of Psychology, 75, 401-410.

Dickerson, M. G., FABRe, J., \& Bayliss, D. (1986). A comparison of TAB customers and poker machine players. In J. McMillen (Ed.), Gambling in the 80's (pp. 13-28). National Association for Gambling Studies, Griffith University, Queensland, Australia.

Dixon, M. R., Hayes, L. J., Rehfeldt, R. A., \& EbBs, R. E. (1998). An adjusting procedure for studying outcomes of risk-taking. Psychological Reports, 82, 1047-1050.

Dixon, M. R., MacLin, O. H., \& Hayes, L. J. (1999). Toward molecular analysis of video poker play. Behavior Research Methods, Instruments, \& Computers, 31, 185-187.

GHEzzI, P., Lyons, C., \& DixON, M. R. (in press). Gambling from a socioeconomic perspective. In W. K. Bickel \& R. E. Vuchinich (Eds.), Reframing health behavior change with behavioral economics. Hillsdale, NJ: Erlbaum.

Kahneman, D., \& Tversky, A. (1972). Subjective probability: A judgement of representativeness. Cognitive Psychologv, 3, 430-454.

Ladouceur, R., Gaboury, A., Dumunt, M., \& Rochette, P. (1988). Gambling: Relationship between the frequency of wins and irrational thinking. Journal of Psychologv, 122, 409-414.

(Manuscript received August 3, 1998; revision accepted for publication January 19,1999 .) 